$\approx \underset{\substack{\text { Journal of } \\ \text { Experimental } \\ \text { Botany }}}{2}$

\title{
Molecular characterization and functional analysis of sucrose-cleaving enzymes in carrot (Daucus carota L.)
}

\author{
Arnd Sturm ${ }^{1}$ \\ Friedrich Miescher-Institut, Postfach 2543, CH-4002 Basel, Switzerland
}

Received 25 October 1995; Accepted 28 October 1995

\begin{abstract}
The amount of carbon transported into storage organs of crop plants to a large degree determines crop yield. The role of sucrose-cleaving enzymes in this process is not clear and it is the main goal of our work to tackle this question. Sucrose cleavage is catalysed either by invertase or sucrose synthase both of which exist in several isoforms with different subcellular locations. Carrot (Daucus carota L.) contains three major isoenzymes of acid invertase, which either accumulate as soluble polypeptides in the vacuole (isoenzymes I and II) or are ionically bound to the cell wall. Carrot sucrose synthase is thought to be a cytoplasmic enzyme encoded by two genes. cDNA clones have been isolated and characterized for cell wall invertase, for isoenzymes I and II of vacuolar invertase, and for sucrose synthase. Gene-specific fragments of these clones were used to determine the steady-state levels of transcripts in the prominent sink and source organs of developing carrot plants. The expression patterns of each gene were different and were organ- and development-specific. Developing tap roots contained only transcripts for isoenzyme II of vacuolar invertase and sucrose synthase. The source/sink balance of these plants was manipulated and only the expression of these two genes was markedly altered, indicating their importance in sucrose partitioning. Based on these results, a model is proposed for sucrose partitioning in carrot plants with developing tap roots in which sucrose synthase regulates sucrose utilization, whereas isoenzyme II of vacuolar invertase controls sucrose storage and sugar composition.
\end{abstract}

Key words: Daucus carota L., expression patterns, invertase, isoenzymes, sucrose partitioning, sucrose synthase.

\section{Introduction}

In most plants, sucrose is the primary product of photosynthesis and also the transport form of assimilated carbon. Whereas some of the sucrose is directly used for leaf growth and maintenance, the majority is transported to the heterotrophic plant organs. Sucrose transport from source cells into sink organs is a multi-step process which includes transport through several membranes and longdistance transport in the sieve tube/companion cell complex (phloem). It is thought that sucrose transport is driven by a turgor pressure gradient generated by a sucrose concentration gradient, with high sucrose concentrations at the site of phloem loading and lower concentrations at the site of phloem unloading ( $\mathrm{Ho}$ and Baker, 1982). The molecular components that generate this concentration gradient are under investigation in many laboratories, and include membrane-located transport proteins and sucrose-cleaving enzymes that catalyse sucrose utilization in the sink organs (Ho, 1988). In this laboratory, molecules involved in sucrose transport into the tap root of carrot (Daucus carota L.) are being identified. In this plant species, sucrose is the transport form of assimilated carbon and also the major storage compound, accumulating in vacuoles of the parenchyma cells of the tap root. Because of this biochemical simplicity, carrot is an ideal model for such a study. In this review, the focus will be on the molecular characterization of sucrose-cleaving enzymes from carrot and their possible functions in sucrose partitioning.

\section{Molecular characterization of sucrose synthase and invertase from carrot}

Plants contain two different sucrose-cleaving enzymes, sucrose synthase and invertase (Copeland, 1990). Sucrose synthase is a glycosyl transferase which converts sucrose

\footnotetext{
' Fax: +416169739 76. E-mail: sturm@fmi.ch
}

(1) Oxford University Press 1996 
in the presence of uridine diphosphate (UDP) into UDPglucose and fructose. In contrast, invertase is a hydrolase which cleaves the disaccharide into glucose and fructose. Sucrose synthase and invertase exist in several isoforms which accumulate in different subcellular compartments. In monocot plants, two isoforms of sucrose synthase are known (Chourey and Nelson, 1976; Chourey, 1981), with fairly similar protein sequences (Huang et al., 1994) but very different regulation at the level of gene expression (Chourey et al., 1986). For a long time it was thought that sucrose synthase was a soluble protein in the cytoplasm, but recent findings have demonstrated that in, for example, cotton fibres about half of the protein is associated with the plasma membrane and appears to be involved in the biosynthesis of cellulose and callose (Delmer and Amor, 1995; Amor et al., 1995). With the exception of Arabidopsis (Chopra et al., 1992; Martin et al., 1993) and potato ( $\mathrm{Fu}$ and Park, 1995), only one gene and one sucrose synthase polypeptide have been found in dicot plants (Salanoubat and Belliard, 1987; Arai et al., 1992; Heim et al., 1993; Wang et al., 1993).

Sucrose synthase has been isolated from carrot roots and characterized at the biochemical level (Šebková et al., 1995). A cDNA clone has been obtained by heterologous cloning with the cDNA for the enzyme from potato (Salanoubat and Belliard, 1987) and because several independent cDNA clones had an identical DNA sequence, it was thought that only one gene existed. This notion was supported by a rather simple hybridization pattern on a genomic DNA gel blot. During a recent search for genomic clones for carrot sucrose synthase, two genes coding for similar, but clearly different, polypeptides were identified (M. Hardegger, S. Schatt, and A. Sturm, unpublished results). A study on the expression of the genes revealed that the gene corresponding to the cDNA is expressed in numerous tissues throughout plant development (Šebková et al., 1995). In contrast, transcripts of the second gene have not been identified, either in a specific organ at a specific developmental stage or as the result of biotic or abiotic stresses (S. Schatt and A. Sturm, unpublished results).

Plant invertases have either alkaline or acidic $\mathrm{pH}$ optima. Alkaline invertase has been characterized in only a few plant species (Ricardo, 1974; Morell and Copeland, 1984; Masuda et al., 1987; Chen and Black, 1992; van den Ende and van Laere, 1995), and is thought to be a cytoplasmic protein (cytoplasmic invertase). Acid invertase ( $\beta$-fructofuranosidase) has been studied extensively (Sturm and Chrispeels, 1990), and accumulates either as a soluble protein in the matrix of the vacuole (vacuolar invertase) or is ionically bound to the cell wall (cell wall invertase).

Alkaline invertase was purified from the soluble fraction of cells of a carrot cell suspension culture and two isoforms with different biochemical characteristics were obtained (Lee and Sturm, 1995). Partial amino acid sequencing revealed no homologies to the acid invertases (A. Sturm, unpublished results). cDNA cloning is in progress.

Carrot contains several acid invertases; a major form of the cell wall enzyme and two forms of vacuolar invertase (isoenzyme I and II). The different isoforms were characterized at the biochemical level and the most abundant form of each compartment was purified (Laurière et al., 1988; Unger et al., 1992). Partial sequences and specific antibodies led to the isolation of their cDNA clones (Sturm and Chrispeels, 1990; Unger et al., 1994). The acid invertases appear to be preproproteins with signal peptides and $\mathrm{N}$-terminal propeptides. A comparison of the amino acid sequences of the leader peptides of the different isoforms showed no homologies. The mature proteins of the vacuolar invertases are very acidic, whereas the cell wall protein is very basic. The vacuolar proteins share some regions of homology with the cell wall enzyme but in parts are quite different, explaining the marked differences in their isoelectric points. The cDNA-derived amino acid sequences of the vacuolar invertases also contain short $\mathrm{C}$-terminal extensions, most likely containing the information for vacuolar targeting (Unger et al., 1994).

The marked differences in the sequences of the different isoforms of acid invertase indicate that each isoenzyme is encoded by a different gene. Genomic gel blots probed with cDNA-specific probes confirmed this hypothesis as the probes hybridized to different DNA fragments. Furthermore, the hybridization patterns obtained were quite simple, suggesting that each of the isoforms is encoded by only one or two genes (Unger et al., 1994). These genes have since been isolated and sequenced (Ramloch-Lorenz et al., 1993; Lorenz et al., 1995; M. Hardegger and A. Sturm, unpublished results). Their overall gene structures are very similar (Plate 1). A comparison of the $5^{\prime}$ upstream sequences revealed no prominent homologies.

In conclusion, the carrot alkaline and acid invertases appear to be unrelated with respect to their protein sequences. The different isoforms of the acid invertases are the products of different but related genes, which is in contrast to the invertases of yeast. Yeast contains a cytoplasmic and an extracellular invertase which originate from one gene by differential splicing (Carlson and Botstein, 1982).

\section{Analysis of the function ot the different isoforms of sucrose synthase and invertase}

Sucrose synthase and invertase have been known for several decades and have been studied in numerous plant species. From these studies it has become clear that the two enzymes play essential roles in plant carbon metabol- 

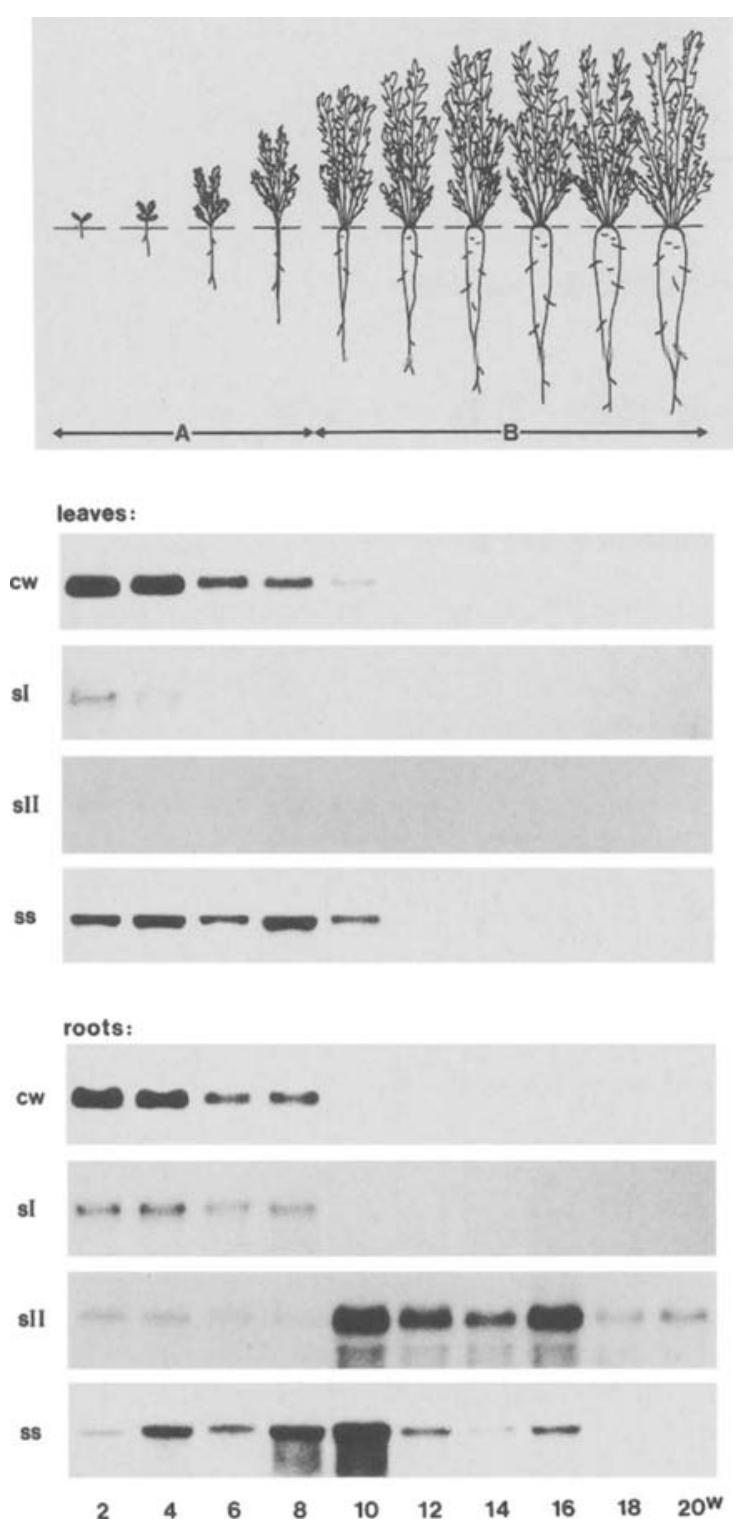

Plate 1. Steady-state mRNA levels for sucrose-cleaving enzymes in leaves and roots of developing carrot plants. Carrots were grown in a field between April and October 1991. Within the first 8 weeks, a primary root developed and leaves grew (first developmental phase). The storage root (tap root) developed and matured between weeks 8 and 20 (second developmental phase). Plants were harvested at 2-week intervals ( 5 plants per time point) and RNA was isolated from leaves and roots. Upper panel: Schematic representation of the development of carrot plants up to 20 weeks post-germination (A, first development phase; B, second development phase). Middle panel: Total RNA (10 $\mu \mathrm{g} /$ lane) from leaves was separated on a formaldehyde-containing agarose gel and transferred to a nylon membrane. Four identical blots were probed with ${ }^{32} \mathrm{P}$-labelled fragments of the cDNAs for carrot cell wall invertase (cw), isoenzymes I (sI) and II (sII) of vacuolar invertase, and sucrose synthase (ss). Lower panel: Identical gel blots with total RN $\Lambda$ from roots $(10 \mu \mathrm{g} /$ lane) probed with the same cDNA fragments. The numbers at the bottom of the panels indicate the ages of the plant organs analysed in weeks post-germination ( $w$, weeks). ism. The presence of different isoforms, with their spatial compartmentation in plant cells and their unique biochemical properties may permit independent control of sucrose metabolism, translocation, and storage, and may facilitate the entry of hexoses into intermediary metabolism (Chen and Black, 1992). The specific functions of the different isoforms are slowly emerging and several hypotheses have been published. It has been suggested that cell wall invertase plays an important role in phloem unloading by creating a steep sucrose concentration gradient between the source tissue and the sink organs (Eschrich, 1980; Morris and Arthur, 1985). It has been proposed that the vacuolar invertases participate in the regulation of the hexose level in mature tissues (Ricardo, 1974, Ricardo and Sovia, 1974) and in the utilization of sucrose stored in vacuoles (Leigh et al., 1979). Recent studies have also suggested participation of vacuolar invertases in sink-strength regulation (Morris and Arthur, 1985; Arai et al., 1991). Others have proposed that the activity of sucrose synthase can be used as a biochemical marker for sink strength (Sung et al., 1989; Sowokinos and Varns, 1992; Sun et al., 1992).

To understand the functions of the different isoforms of the carrot sucrose-cleaving enzymes, it is important to know when and where their genes are expressed. The steady-state transcript levels for the different isoforms of sucrose synthase and invertase were therefore determined in source and sink organs of developing carrot plants by RNA gel blot analysis (Sturm et al., 1995). As probes, gene-specific fragments of the cDNA clones described above were used.

Data from this laboratory show an individual expression pattern for the genes analysed, indicating a different function for each enzyme (Fig. 1). Only plants with primary roots contained high and about equal levels of transcripts for cell wall invertase in leaf lamina, petioles and roots; thus the expression of the gene is developmentspecific, but not organ-specific. In contrast, expression of the genes for isoenzyme I and II of vacuolar invertase seems to be under spatial and temporal control. High levels of transcripts for both isoenzymes were only found in roots, with the highest levels of isoenzyme I transcripts in primary roots and isoenzyme II in developing tap roots. Transcripts for sucrose synthase were found in all developing plant organs. The transcript level appears to be highly regulated, with markedly elevated levels in young leaves and in roots at the transition from primary to secondary roots.

In developing tap roots, only transcripts for sucrose synthase and isoenzyme II of vacuolar invertase were detected, suggesting their involvement in sucrose partitioning. In contrast, transcripts for isoenzyme I and cell wall invertase were not found, making their participation very unlikely. In order to support this finding, the sink/ source balance of carrot plants was altered and the 


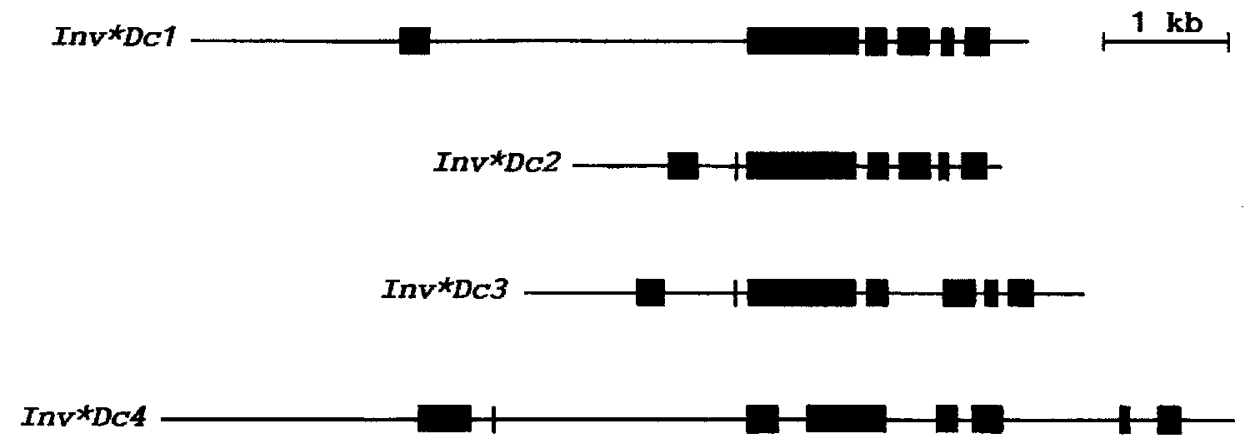

InV*DC5

Fig. 1. Structural maps of genomic clones for cell wall invertase and vacuolar invertase from carrot. $\ln v^{*} D c 1, \operatorname{In} v^{*} D c 2$, and $\operatorname{In} v^{*} D c 3 \operatorname{code}$ for cell wall invertase and related enzymes (Lorenz et al., 1995). Inv*Dc4 and $I n v^{*} D c 5$ code for isoenzyme I and II of vacuolar invertase (M. Hardegger and A. Sturm, unpublished results). The coding regions are represented as black boxes with intervening and non-coding sequences shown as lines.

expression patterns for the genes for the sucrose-cleaving enzymes analysed (Sturm et al., 1995). Only the expression of isoenzyme II of vacuolar invertase and sucrose synthase markedly changed, supporting their involvement in sucrose partitioning. Transcripts of cell wall invertase and isoenzyme I of vacuolar invertase were not detected throughout the experiment, providing further evidence that these enzymes have no function in this process.

\section{A model for sucrose partitioning in carrot plants with developing tap roots}

Sucrose, the first non-phosphorylated product of carbon assimilation, is synthesized in the cytoplasm of the leaf mesophyll cells (Fig. 2), from where it is transported to the developing tap root. Phloem loading requires the transport of the disaccharide across at least two membranes. It is widely believed that the disaccharide passively diffuses through their plasma membranes into the extracellular space due to the high sucrose concentration in the mesophyll cells (van Bel, 1993). Transport of sucrose from the apoplast into the phloem is catalysed by a $\mathrm{H}^{+}$/sucrose co-transporter of the companion cell plasma membrane and is driven by ATP hydrolysis at the cytoplasmic side of the transport protein (Daie, 1989). The ATP needed is generated in the companion cells by catabolism of some of the sucrose, which may require the activity of sucrose synthase for sucrose cleavage (Nolte and Koch, 1993). The companion cells and the sieve tubes appear to be connected by numerous plasmodesmata and are considered as one compartment with respect to transport of photoassimilates (Kempers et al., 1993).

Sucrose transport between source and sink organs seems to be driven by a turgor pressure gradient caused by a sucrose concentration gradient (Ho and Baker, 1982). For sugar-storing sinks such as carrot tap roots, where osmotically active solutes are stored against a

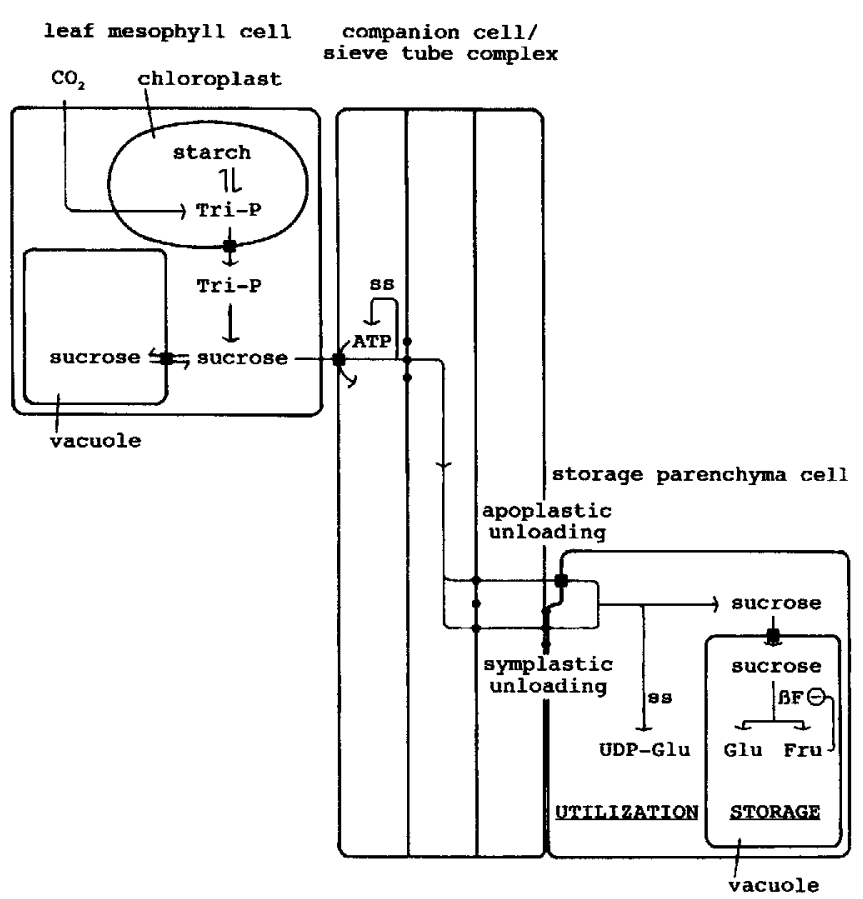

Fig. 2. Model for sucrose partitioning in carrot plants with developing tap roots. Sucrose is synthesized in leaf mesophyll cells and utilized or stored in storage parenchyma cells of the developing tap root. Black squares represent membrane-located pumps and black circles plasmodesmata. $\beta \mathrm{F}$, invertase; ss, sucrose synthase; Tri-P, triose phosphate.

concentration gradient, an apoplastic unloading step has been suggested (Ho, 1988; Patrick, 1990). In contrast to the model postulated by Eschrich (1980), sucrose is transported without prior cleavage from the apoplast into the parenchyma cells of the carrot tap root (Daie, 1984). Dependent on the developmental state of these cells, sucrose is utilized for growth and development (utilization sink) and/or imported into the vacuoles for storage (storage sink). In contrast to Eschrich's model, in which cleavage of the sucrose by cell wall invertase was the 
driving force of phloem unloading, in our model (Fig. 2) this process is driven by sucrose utilization in the cytoplasm and storage in the vacuole. Because transport of sucrose into carrot parenchyma cells occurs at least partially through membrane-located pumps (Daie, 1984; Hole and Dearman, 1994), active translocation of the disaccharide through the plasmalemma may also drive this process.

In developing carrot tap roots (utilization sink), cytoplasmic cleavage of sucrose for utilization appears to be catalysed by sucrose synthase. The UDP-glucose generated by sucrose synthase is a general intermediate for the biosynthesis of cell wall polysaccharides, amino acids, lipids etc. At later stages of tap root development (storage sink), storage of sugars is the main cellular activity. For this purpose sucrose is transported into the vacuoles against a sucrose gradient, which is carrier-mediated and requires energy (Getz, 1991; Getz et al., 1993). Compartmentation of sucrose in the vacuole and its subsequent cleavage by a vacuolar invertase now generate and maintain the sucrose concentration gradient and thereby participate in driving the flow of sucrose from leaves into roots. Because the activity of the vacuolar invertase is inhibited by millimolar concentrations of fructose (Sampietro et al., 1980; Lopez et al., 1988; Isla et al., 1991), sucrose cleavage does not go to completion and the sugars stored in mature tap roots are a mixture of sucrose, fructose and glucose.

This model for sucrose partitioning can also be applied to plants in which photoassimilates are unloaded symplastically (Fig. 2). In this extended and now fairly general model, unloading may occur either via a symplastic or an apoplastic route. Sink strength is now generated by the common action of sucrose synthase and vacuolar invertase and, especially in the case of apoplastic unloading, by the directed and active transport of sucrose across membranes.

The model presented above only assigned functions to one isoform of sucrose synthase and to acid invertase. Alternative functions of these and possible functions of the other enzymes have been discussed in detail in a previous publication (Sturm et al, 1995). To test the model, transgenic carrot plants with altered expression of the different enzymes by sense/antisense transformation are currently being generated.

\section{Acknowledgements}

I thank my colleagues Markus Hardegger, Hoi-Seon Lee, Susanne Lienhard, Kathrin Lorenz, Stephan Schatt, Veronika Šebková, and Christoph Unger for their valuable experimental contributions. I also acknowledge Markus Hardegger, Patrick King and Hoi-Seon Lee for critical reading of the manuscript.

\section{References}

Amor Y, Haigler CH, Johnson S, Wainscott M, Delmer DP. 1995. A membrane-associated form of sucrose synthase and its potential role in synthesis of cellulose and callose in plants. Proceedings of the National Academy of Sciences, USA 92, 9353-7.

Arai M, Mori H, Imaseki H. 1991. Roles of sucrose-metabolizing enzymes in growth of seedlings. Purification of acid invertase from growing hypocotyls of mung bean seedlings. Plant Cell Physiology 32, 1291-8.

Arai M, Mori H, Imaseki H. 1992. Expression of the gene for sucrose synthase during growth of mung bean seedlings. Plant Cell Physiology 33, 503-6.

Carlson M, Botstein D. 1982. Two differentially regulated mRNAs with different $5^{\prime}$ ends encode secreted and intracellular forms of yeast invertase. Cell 28, 145-54.

Chen JQ, Black CC. 1992. Biochemical and immunological properties of alkaline invertase isolated from sprouting soybean hypocotyls. Archives of Biochemistry and Biophysics 295, 61-9.

Chopra S, Del-favero J, Dolferus R, Jacobs M. 1992. Sucrose synthase of Arabidopsis: Genomic cloning and sequence characterization. Plant Molecular Biology 18, 131-4.

Chourey PS. 1981. Genetic control of sucrose synthetase in maize endosperm. Molecular and General Genetics 184, 372-6.

Chourey PS, Latham MD, Still PE. 1986. Expression of two sucrose synthetase genes in endosperm and seedling cells of maize: evidence of tissue specific polymerization of protomers. Molecular and General Genetics 203, 251-5.

Chourey PS, Nelson OE. 1976. The enzymatic deficiency conditioned by the shrunken-1 mutations in maize. Biochemical Genetics 14, 1041-55.

Copeland L. 1990. Enzymes of sucrose metabolism. Methods in Plant Biochemistry 3, 73-85.

Daie J. 1984. Characterization of sugar transport in storage tissue of carrot. Journal of the American Society of Horticultural Science 109, 718-22.

Daie J. 1989. Phloem loading of sucrose: update and opportunities in molecular biology. Plant Molecular Biology Reporter 7, 106-15.

Delmer DP, Amor Y. 1995. Cellulose biosynthesis. The Plant Cell 7, 987-1000.

Eschrich W. 1980. Free space invertase, its possible role in phloem unloading. Berichte der Deutschen Botanischen Gesellschaft 93, 363-78.

Fu H, Park WD. 1995. Sink and vascular-associated sucrose synthase functions are encoded by different gene classes in potato. The Plant Cell 7, 1369-85.

Getz HP. 1991. Sucrose transport in tonoplast vesicles of red beet roots is linked to ATP hydrolysis. Planta 185, 261-8.

Getz HP, Grosclaude J, Kurkdjian A, Lelièvre F, Maretzki A, Guern J. 1993. Immunological evidence for the existence of a carrier protein for sucrose transport in tonoplast vesicles from red beet (Beta vulgaris L.) root storage tissue. Plant Physiology 102, 751-60.

Heim U, Weber H, Baumlein H, Wobus U. 1993. A sucrosesynthase gene of Vicia faba L.: expression pattern in developing seeds in relation to starch synthesis and metabolic regulation. Planta 191, 394-401.

Ho LC. 1988. Metabolism and compartmentation of imported sugars in sink organs in relation to sink strength. Annual Review of Plant Physiology and Plant Molecular Biology 39, 355-78.

Ho LC, Baker DA. 1982. Regulation of loading and unloading 
in long distance transport systems. Physiologia Plantarum 56, 225-30.

Hole CC, Dearman J. 1994. Sucrose uptake by the phloem parenchyma of carrot storage root. Journal of Experimental Botany 45, 7-15.

Huang XF, Quoc BN, Chourey PS, Yelle S. 1994. Complete nucleotide sequence of the maize (Zea mays L.) sucrose synthase 2 cDNA. Plant Physiology 104, 293-4.

Isla MI, Vattuone MA, Sampietro AR, 1991. Modulation of potato invertase activity by fructose. Phytochemistry 30, $423-6$.

Kempers R, Prior DAM, van Bel AJE, Oparka KJ. 1993. Plasmodesmata between sieve element and companion cell of extrafascicular stem phloem of Cucurbita maxima permit passage of $3 \mathrm{kDa}$ fluorescent probes. The Plant Journal $4,567-75$.

Laurière M, Laurière C, Sturm A, Faye L, Chrispeels MJ. 1988. Characterization of $\beta$-fructosidase, an extracellular glycoprotein of carrot cells. Biochimie 70, 1483-91.

Lee H-S, Sturm A. 1995. Characterization of neutral and alkaline sucrase from carrot. Plant Physiology 108, (supplement), 73.

Leigh RA, ap Rees T, Fuller WA, Banfield J. 1979. The location of acid invertase activity and sucrose in the vacuoles of storage roots of beetroots (Beta vulgaris). Biochemical Journal 178, 539-47.

Lopez ME, Vattuone MA, Sampietro AR. 1988. Partial purification and properties of invertase from Carica papaya fruits. Phytochemistry 27, 3077-81.

Lorenz K, Lienhard S, Sturm A. 1995. Structural organization and differential expression of carrot $\beta$-fructofuranosidase genes: identification of a gene coding for a flower bud-specific isozyme. Plant Molecular Biology 28, 189-94.

Martin T, Frommer WB, Salanoubat M, Willmitzer L. 1993. Expression of an Arabidopsis sucrose synthase gene indicates a role in metabolization of sucrose both during phloem loading and in sink organs. The Plant Journal 4, 367-77.

Masuda H, Takahashi T, Sugawara S. 1987. The occurrence and properties of alkaline invertase in mature roots of sugar beets. Agricultural and Biological Chemistry 51, 2309-14.

Morell M, Copeland L. 1984. Enzymes of sucrose breakdown in soybean nodules. Plant Physiology 74, 1030-4.

Morris DA, Arthur ED. 1985. Effects of gibberellic acid on patterns of carbohydrate distribution and acid invertase activity in Phaseolus vulgaris. Physiologia Plantarum 65, 257-62.

Nolte KD, Koch KE. 1993. Companion-cell specific localization of sucrose synthase in zones of phloem loading and unloading. Plant Physiology 101, 899-905.

Patrick JW. 1990. Sieve element unloading: cellular pathway, mechanism and control. Physiologia Plantarum 78, 298-308.
Ramloch-Lorenz K, Knudsen S, Sturm A. 1993. Molecular characterization of the gene for carrot cell wall $\beta$-fructosidase. The Plant Journal 4, 545-54.

Ricardo CPP. 1974. Alkaline $\beta$-fructosidase of tuberous roots: possible physiological function. Planta 118, 333-43.

Ricardo CPP, Sovia D. 1974. Development of tuberous roots and sugar accumulation as related to invertase activity and mineral nutrition. Planta 114, 43-55.

Salanoubat M, Belliard G. 1987. Molecular cloning and sequencing of sucrose synthase from potato (Solanum tuberosum L.): preliminary characterization of sucrose synthase mRNA distribution. Gene 60, 47-56.

Sampietro AR, Vattuone MA, Prado FE. 1980. A regulatory invertase from sugar cane leaf-sheaths. Phytochemistry 19 $1637-42$.

Šebková V, Unger C, Hardegger, Sturm A. 1995. Biochemical, physiological, and molecular characterization of sucrose synthase from Daucus carota. Plant Physiology 108, 75-83.

Sowokinos JR, Varns JL. 1992. Induction of sucrose synthase in potato tissue culture: effect of carbon source and metabolic regulators on sink strength. Journal of Plant Physiology 139, 672-9.

Sturm A, Šcbková V, Lorenz K, Hardegger M, Lienhard S, Unger C. 1995. Developmental- and organ-specific expression of the genes for sucrose synthase and three isoenzymes of acid $\beta$-fructofuranosidase in carrot. Planta 195, 601-10.

Sturm A, Chrispeels MJ. 1990. cDNA cloning of carrot extracellular $\beta$-fructosidase and its expression in response to wounding and bacterial infection. The Plant Cell 2, 1107-19.

Sun J, Loboda T, Sung SS, Black Jr CC. 1992. Sucrose synthase in wild tomato, Lycopersicon chmielewskii, and tomato fruit sink strength. Plant Physiology 98, 1163-9.

Sung S-JS, Xu D-P, Black CC. 1989. Identification of actively filling sucrose sinks. Plant Physiology 89, 1117-21.

Unger C, Hardegger M, Lienhard S, Sturm A. 1994. cDNA cloning of carrot soluble acid $\beta$-fructofuranosidases and comparison with the cell wall isoenzyme. Plant Physiology $104,1351-7$.

Unger C, Hofsteenge J, Sturm A. 1992. Purification and characterization of a soluble $\beta$-fructofuranosidase from Daucus carota. European Journal of Biochemistry 204, 915-21.

van Bel AJE. 1993. Strategies of phloem loading. Annual Review of Plant Physiology and Plant Molecular Biology 44, 253-81.

van den Ende W, van Laere A. 1995. Purification and properties of a neutral invertase from the roots of Cichorium intybus. Physiologia Plantarum 93, 241-8.

Wang F, Sanz A, Brenner ML, Smith A. 1993. Sucrose synthase, starch accumulation, and tomato fruit sink strength. Plant Physiology 101, 321-7. 